\title{
Insecticidal activity of Leptodactylus knudseni and Phyllomedusa vaillantii crude skin secretions against the mosquitoes Anopheles darlingi and Aedes aegypti
}

Frances $T$ Trindade ${ }^{1,2}$, Ângela A Soares ${ }^{3}$, Andréa A de Moura ${ }^{3}$, Tiago B Rego ${ }^{3}$, Andreimar M Soares ${ }^{3}$, Rodrigo G Stábeli ${ }^{2,3}$, Leonardo A Calderon ${ }^{2,3}$ and Alexandre de Almeida e Silva ${ }^{1,2^{*}}$

\begin{abstract}
Background: Mosquitoes are important vectors of several diseases, including malaria and dengue, and control measures are mostly performed using chemical insecticides. Unfortunately, mosquito resistance to commonly applied insecticides is widespread. Therefore, a prospection for new molecules with insecticidal activity based on Amazon biodiversity using the anurans Leptodactylus knudseni and Phyllomedusa vaillantii was performed against the mosquito species Anopheles darlingi and Aedes aegypti.
\end{abstract}

Methods: The granular secretion from anuran skin was obtained by manual stimulation, and lethal concentrations (LCS) for larvicidal and adulticidal tests were calculated using concentrations from 1-100 ppm. The skin secretions from the anuran species tested caused significant mortality within the first 24 hours on adults and larvae, but differed within the mosquito species.

Results: The skin secretions from the anuran species tested caused significant mortality within the first 24 hours on adults and larvae, but differed within the mosquito species. The calculated $\mathrm{LC}_{50}$ of $L$. knudseni skin secretions against An. darlingi was 0.15 and $0.2 \mathrm{ppm}$ for adults and larvae, respectively, but much higher for Ae. aegypti, i.e., 19 and $38 \mathrm{ppm}$, respectively. Interestingly, the calculated $L C_{50}$ of $P$. vaillantii against both mosquito species in adults were similar, 1.8 and 2.1 ppm, respectively, but the $\mathrm{LC}_{50}$ for An. darlingi larvae was much lower ( $0.4 \mathrm{ppm}$ ) than for Ae aegypti (2.1 ppm).

Conclusions: The present experiments indicate that skin secretions from $L$. knudseni and $P$. vaillantii contain bioactive molecules with potent insecticide activity. The isolation and characterization of skin secretions components will provide new insights for potential insecticidal molecules.

Keywords: Vector control, Anuran amphibians, Dengue, Malaria

\section{Background}

Mosquitoes are important vectors of several diseases, including malaria and dengue fever [1]. According to the World Health Organization (WHO) [2] there were approximately 675,000 confirmed cases in 2011 of dengue fever among 19 American countries. In Brazil, most of

\footnotetext{
*Correspondence: alealsil@unir.br

'Laboratory of Insect Bioecology, Department of Biology, Federal University

of Rondônia (UNIR), Porto Velho, Rondônia State, Brazil

${ }^{2}$ Oswaldo Cruz Foundation - Rondônia (Fiocruz - Rondônia), Porto Velho, Rondônia State, Brazil

Full list of author information is available at the end of the article
}

the malaria cases occur in the northern region. Rondônia state, western Amazon, Brazil, recorded 14,510 cases in 2013, mostly transmitted by the mosquito Anopheles darlingi [3,4]. In 2013, of the approximately 204,650 cases of dengue fever in Brazil, 18,435 were recorded in the northern region and were transmitted by the dengue main vector, Aedes aegypti [5].

Vector control is mostly performed using insecticides, but, unfortunately, vector resistance is widespread among mosquitoes. Malaria mosquito resistance surveillance data from 87 countries indicated that 45 of them reported 
resistance to at least one insecticide used as malaria control, including pyrethroids, organophosphates and carbamates [2].

Therefore, prospection for new insecticidal molecules based on rich biodiversity sites such as the Amazon region is often performed, since microorganisms, plants and animals provide a great source of molecules for new potential drugs.

The Amazon fauna also provides the highest number of anuran species in the world and venom glands from frogs contain a variety of substances with pharmaceutical effects against tropical diseases including malaria and leishmaniasis [6,7].

Phyllomedusa vaillantii, a tree frog species, is often found in trees and bushes close to streams or permanent bodies of water in tropical rainforests from several countries in South America and along the Amazon basin [8]. Phyllomedusa skin secretion contains a rich biological mixture of peptides including antimicrobials $[9,10]$.

Leptodactylus knudseni, also known as the Amazonian toad-frog, is a native frog species found in the tropical forest floor and burrows from South and Central America [11]. According to Erspamer [12], extracts from Leptodactylus skin were possibly used to prepare some "curares" by South American natives. The skin secretions of leptodactylids are characterized by a particular composition of amines, among them biogenic amines derivatives from imidazole, indole and phenyl-alkylamides such as leptodactyline, candicine, histamine and serotonine [13]. Besides biogenic amines, Toledo and Jared [14] also mentioned bioactive peptides such as caerulein and physalaemin in leptodactylids.

Although very few reports on the activity of anuran skin secretions on mosquitoes or other dipterans are available; some indicate that crude secretions or their components display insecticidal activity, contact toxicity and repellence [15-17]. The aim of the present study was to investigate the insecticidal activity of crude skin secretions extracted from the frogs Leptodactylus knudseni and Phyllomedusa vaillantii on the main vectors of malaria and dengue fever in Brazil, Anopheles darlingi and Aedes aegypti, respectively.

\section{Methods}

Animal material and crude skin secretions

Phyllomedusa vaillantii and Leptodactylus knudseni adult specimens were collected in Porto Velho, Rondônia, Brazil. Voucher specimens were identified by A. P. Lima and L. A. Calderon and deposited in the Herpetofauna Reference Collection of Rondônia (in Portuguese, Coleção de Referência da Herpetofauna de Rondônia - CRHRO) of the Federal University of Rondônia. Animals were kept inside the terrarium at the Center for the Study of Biomolecules Applicable to Health (Centro de Estudos de Biomoléculas Aplicadas à Saude - CEBio).

The granular secretion from anuran skin was obtained by manual stimulation. The dorsal glandular area of each individual was rinsed with deionized water, clarified by centrifugation, frozen, lyophilized and stored at $-20^{\circ} \mathrm{C}$ until insecticidal assays set up.

\section{Mosquito collection and breeding}

Anopheles darlingi females were collected using a modified BG BG-Sentinel ${ }^{\mathrm{Im}}$ Trap (BioQuip Products, USA) in the municipality of Candeias do Jamari, $\mathrm{RO}\left(8^{\circ} 46^{\prime} 55^{\prime \prime}\right.$ W, $63^{\circ} 42^{\prime} 9^{\prime \prime}$ ) and sent to the Laboratory of Entomology at Fiocruz - Rondônia. Aedes aegypti eggs were obtained from the laboratory strain of the Laboratory of Chemical Ecology of Vector Insects (Laboratório de Ecologia Química de Insetos Vetores), UFMG, Brazil, and reared under laboratory conditions $\left(28^{\circ} \mathrm{C}, 80 \% \mathrm{RU}\right.$ and 12 hour photoperiod). Then, adult mosquitoes were

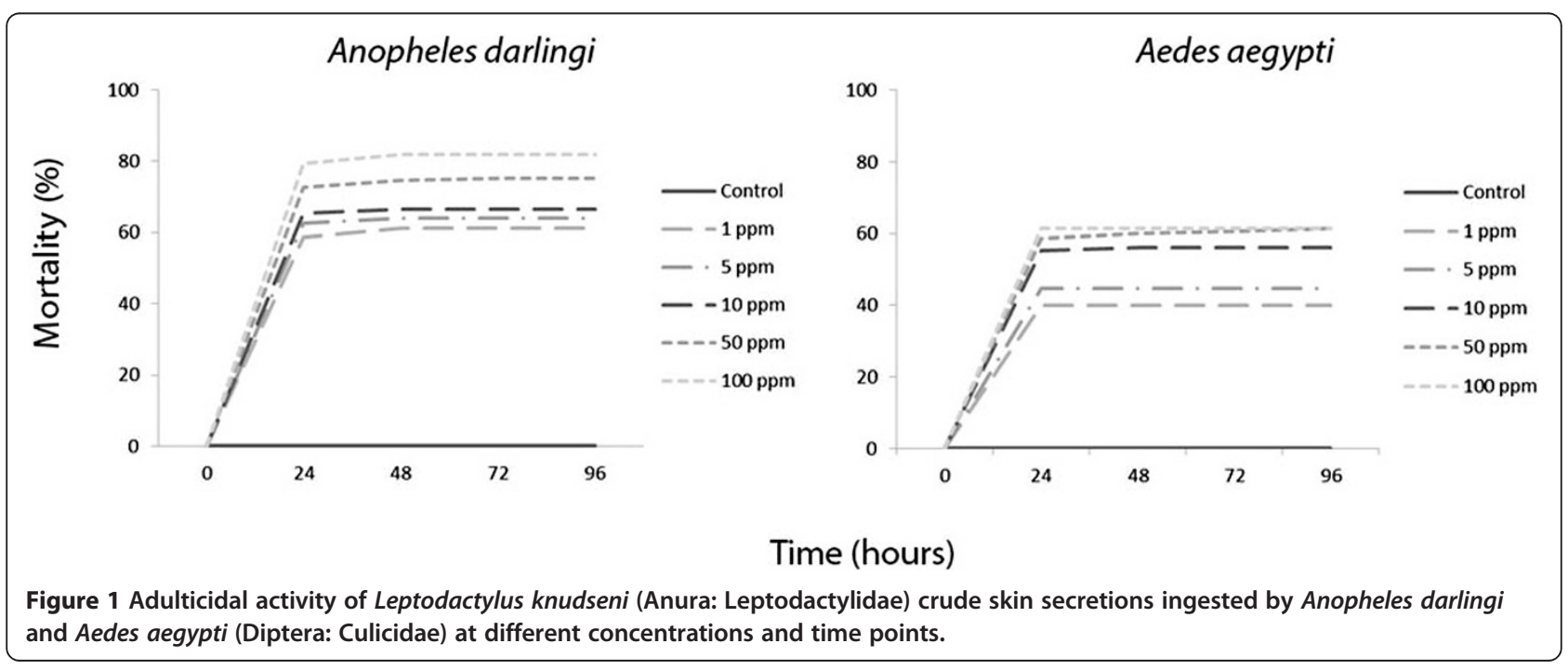




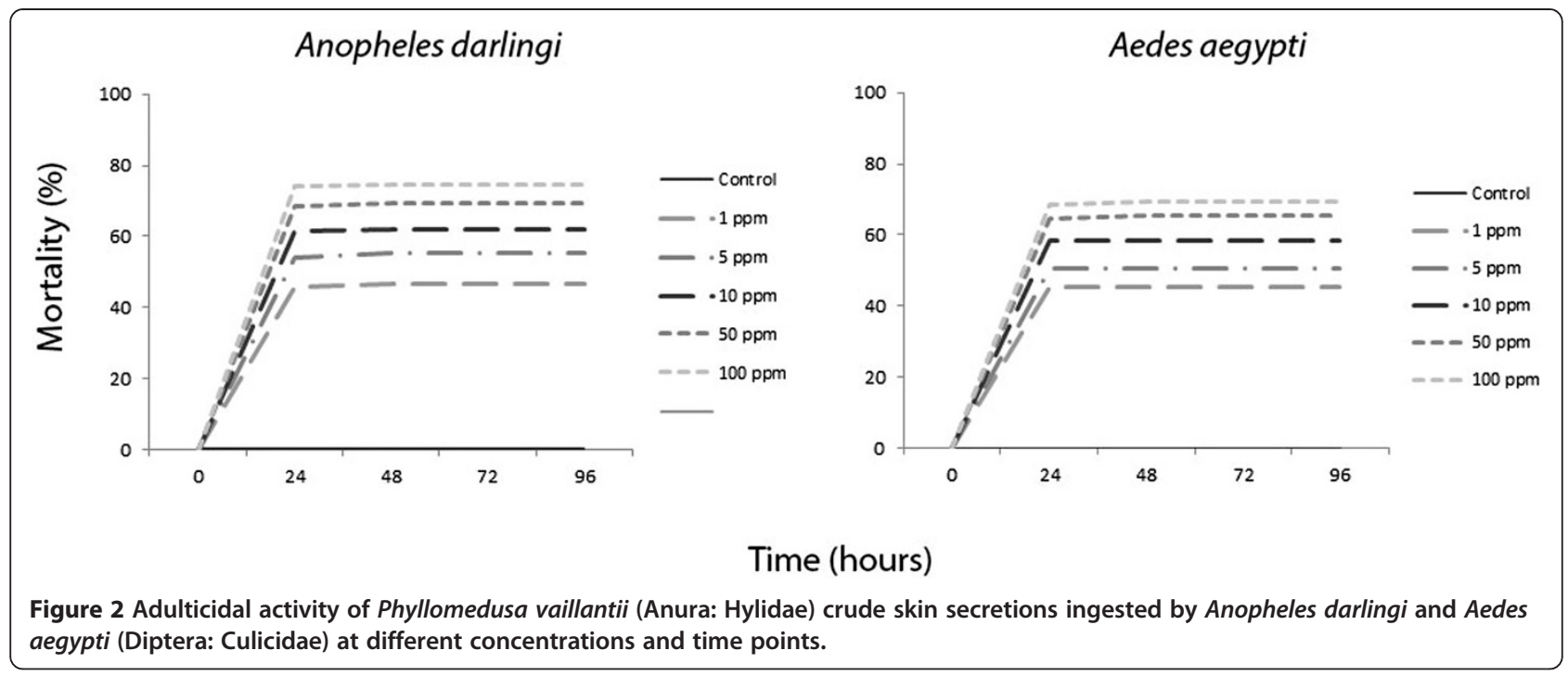

blood fed on rabbits and three days after, $A$. darlingi females were induced to oviposition by removing one of their wings. Ae. aegypti females laid eggs naturally in beaker-containing filter paper and distilled water. After hatching, the larvae were kept under laboratory conditions and fed with fish food (TetraMin ${ }^{\circ}$ Tropical Flakes) up to $3^{\text {rd }}$ and $4^{\text {th }}$ instar, this stage being used for testing larvicides. In order to obtain adults for testing adulticide products, the same methodology was followed up to the pupal stage, when the animals were separated and transferred to larger cages.

\section{Insecticidal activity bioassays}

The lethal concentrations $\left(\mathrm{LC}_{50}\right.$ and $\left.\mathrm{LC}_{90}\right)$ for adult and larval mosquitoes were determined using five different concentrations (ppm: 1, 5, 10, 50, 100), each with four replicates and repeated three times on different occasions [18]. For testing larvicides, crude skin secretions of L. knudseni and P. vaillanti were diluted in water and pipetted under the surface of water in plastic cups $(50 \mathrm{~mL})$ containing $10 \mathrm{~mL}$ of distilled water and larvae (25 larvae per container) introduced in the cups 30 minutes after pipetting. For testing adulticides, crude skin secretions were diluted in $20 \%$ sucrose and pipetted on the screens of cages containing 25 mosquitoes each (30 drops of $2 \mu \mathrm{L} /$ cage); for this mosquitoes were kept without food for 24 hours. After 30 minutes, the engorged mosquitoes were separated. The mortality of larvae and adults was recorded from 24 to 96 hours; however, the calculation of the lethal concentrations included only the 24-48 hours mortality records. The lethal concentrations (LCs) for adulticidal and larvicidal activity of skin secretions against mosquitoes were calculated

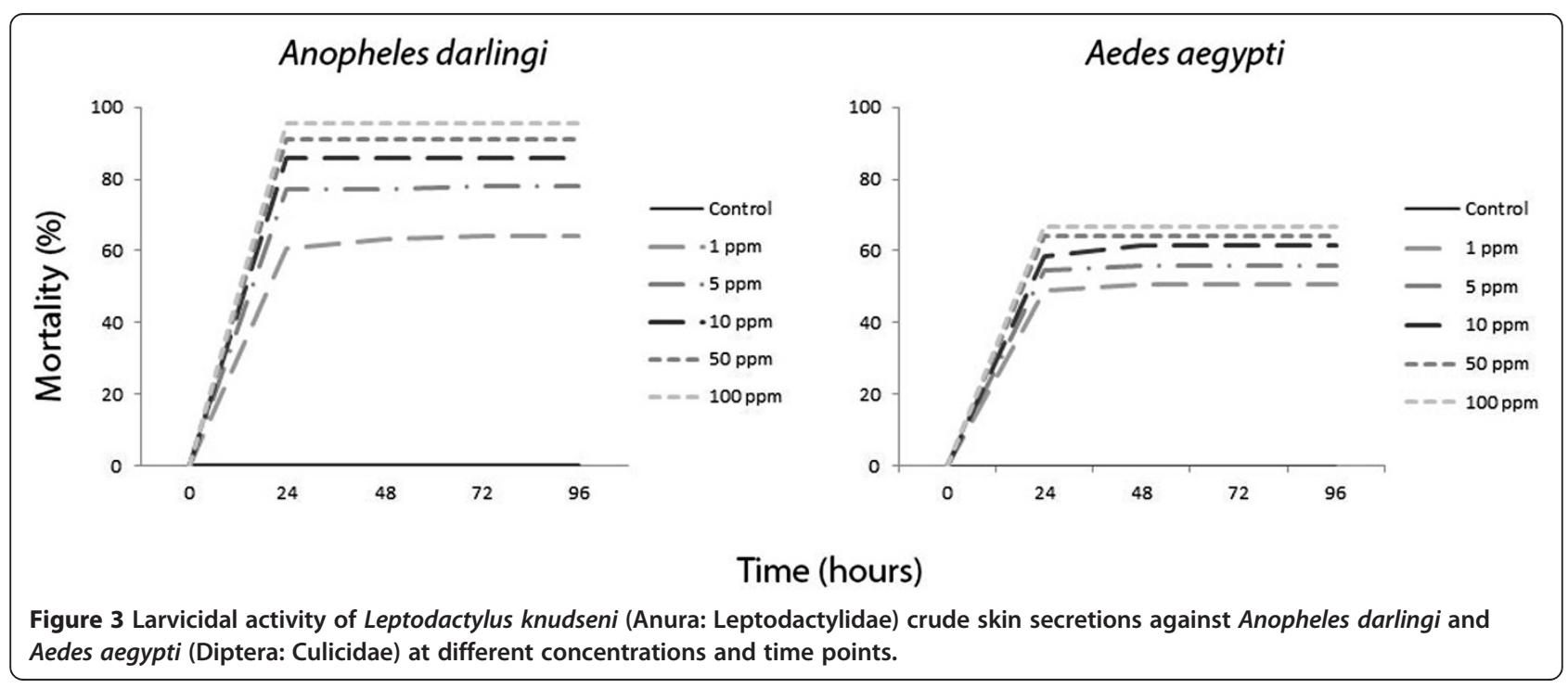




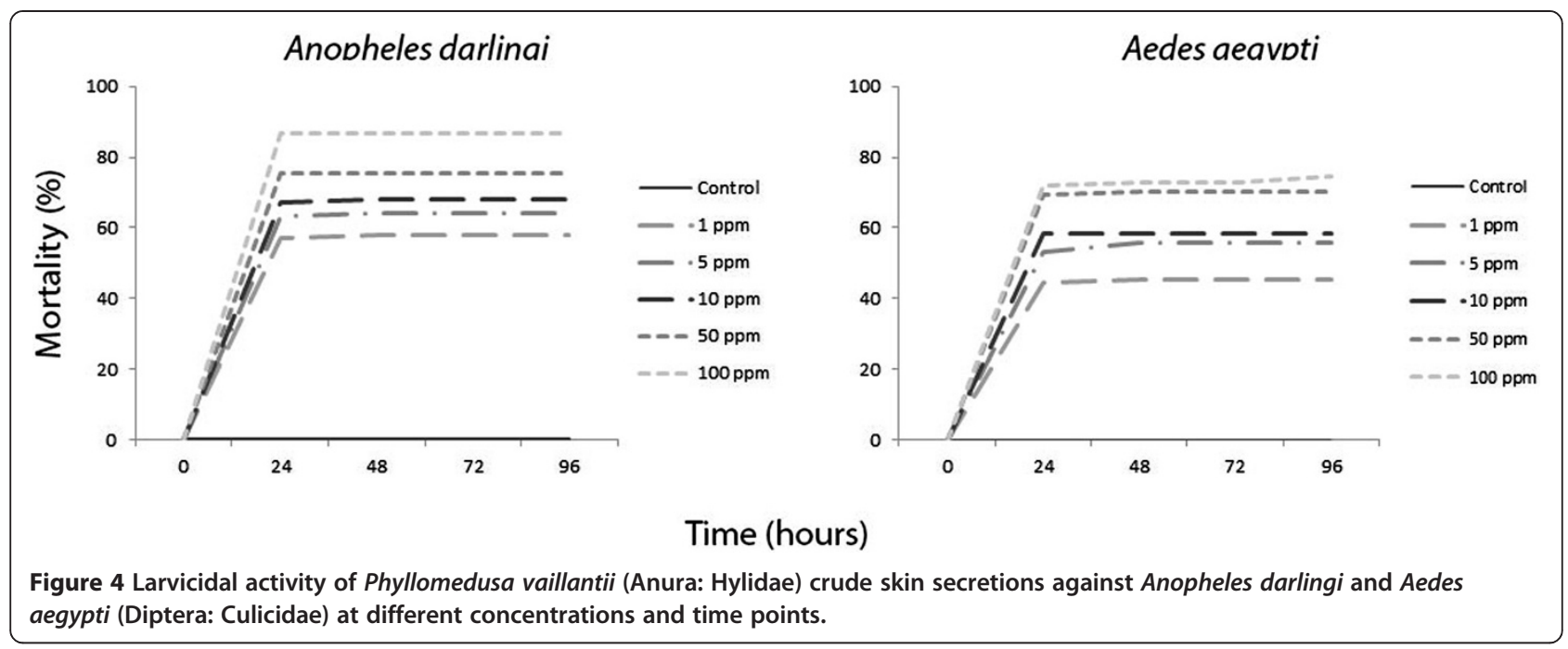

using Probit analysis (Minitab, Minitab Inc). The effects of crude skin secretions on concentration and mortality for larvae and adults were analyzed by Anova on ranks (SigmaStat 2.0, 1992-1997).

\section{Results and discussion}

Skin secretions from the amphibian anurans Leptodactylus knudseni and Phyllomedusa vaillantii caused significant mortality ( $\mathrm{p}<0.001$ ) on adults and larvae of the mosquitoes $A n$. darlingi and Ae. aegypti in a concentration-dependent mortality rate. Mortality peaked in 24 hours with no significant increase afterwards (Figures 1, 2, 3 and 4).

The mortality observed for adults of An. darlingi and Ae. aegypti increased significantly after oral ingestion of 1 to $100 \mathrm{ppm}$ of skin secretions from L. knudseni $(\mathrm{H}=76.06$, $\mathrm{p}<0.001 ; \mathrm{H}=18.78, \mathrm{p}<0.001$, respectively) and $P$. vaillantii $(\mathrm{H}=77.54, \mathrm{p}<0.001 ; \mathrm{H}=18.72, \mathrm{p}<0.001$ respectively).

Anopheles darlingi adults were more susceptible to the ingestion of $L$. knudseni skin secretions, reaching $61 \%$ of mortality with $1 \mathrm{ppm}$, while Ae. aegypti reached the same percentage at only with $100 \mathrm{ppm}$ (Figure 1). Moreover, An. darling and Ae. aegypti had similar susceptibility to the ingestion of $P$. vaillantii skin secretions,

Table 1 Lethal concentrations (LC) in ppm for the crude skin secretions of Leptodactylus knudseni (Anura: Lepdodactylidae) and Phyllomedusa vaillantii (Anura: Hylidae) against Anopheles darlingi and Aedes aegypti (Diptera: Culicidae)

\begin{tabular}{lccccc}
\hline \multirow{2}{*}{$\begin{array}{c}\text { Anura } \\
\text { species }\end{array}$} & \multicolumn{2}{c}{ Adult } & & \multicolumn{2}{c}{ Larvae } \\
\cline { 2 - 3 } \cline { 5 - 6 } & $\begin{array}{c}\text { An. darlingi } \\
\mathrm{LC}_{\mathbf{5 0}}\end{array}$ & $\begin{array}{c}\text { Ae. aegypti } \\
\text { LC }_{\mathbf{5 0}}\end{array}$ & & $\begin{array}{c}\text { An. darlingi } \\
\mathbf{L C}_{\mathbf{5 0}}\end{array}$ & $\begin{array}{c}\text { Ae. aegypti } \\
\text { LC }_{\mathbf{5 0}}\end{array}$ \\
\hline L. knudseni & 0.15 & 19 & & 0.2 & 38 \\
P. vaillantii & 1.8 & 2.1 & & 0.4 & 2.1 \\
\hline
\end{tabular}

PPM: parts per million, $\mathrm{LC}_{50}$ : lethal concentration necessary to kill $50 \%$ of the larvae during assays. i.e., $46 \%$ and $45 \%$ mortality at $1 \mathrm{ppm} ; 74 \%$ and $69 \%$ at $100 \mathrm{ppm}$, respectively (Figure 2). When pooled together, mortality data indicate that $A n$. darlingi and Ae. aegypti adults were more susceptible to the skin secretions of L. knudseni than to P. vaillantii (Table 1).

Similar to adults, the larvicidal effect of anuran skin secretions on both mosquito species increased significantly with the concentration range evaluated (i.e., 1 to 100 ppm) (Figure 3). At 100 ppm, L. knudseni skin secretions killed 96\% of An. darlingi $(\mathrm{H}=77.25, \mathrm{p}<0.001)$ after 24 hours but only $66 \%$ of Ae aegypti $(\mathrm{H}=18.79$, $\mathrm{p}<0.001$ ) at the same concentration (Figure 4). The larvae of $A n$. darlingi, but not those of Ae. aegypti, were remarkably more susceptible to the skin secretions from L. knudseni and P. vaillantii (Table 1).

Although statistically significant, mortality differences between mosquito species at the concentrations tested decreased when larvicidal tests were performed using P. vaillantii skin secretions at $100 \mathrm{ppm}$, i.e. $88 \%$ and $72 \%$ for An. darlingi and Ae. aegypti $(\mathrm{H}=76.78, \mathrm{p}<0.001)$, respectively.

Table 2 General insecticidal activity (median \% of mortality) effect of the crude skin secretions of Leptodactylus knudseni (Anura: Lepdodactylidae) and Phyllomedusa vaillantii (Anura: Hylidae) against Anopheles darlingi and Aedes aegypti (Diptera: Culicidae)

\begin{tabular}{cccccc}
\hline \multirow{2}{*}{$\begin{array}{c}\text { Anura } \\
\text { species }\end{array}$} & \multicolumn{2}{c}{ Adult } & & \multicolumn{2}{c}{ Larvae } \\
\cline { 2 - 3 } \cline { 5 - 6 } \cline { 5 - 6 } & An. darlingi & Ae. aegypti & & An. darlingi & Ae. aegypti \\
\hline L. knudseni & $65.3 \mathrm{a} 1$ & $56.0 \mathrm{~b} 1$ & & $86.0 \mathrm{c} 1$ & $58.7 \mathrm{~d} 1$ \\
P. vaillantii & $61.3 \mathrm{a} 2$ & $58.7 \mathrm{a} 2$ & & $68.0 \mathrm{~b} 2$ & $58.7 \mathrm{a} 1$ \\
\hline
\end{tabular}

Kruskal-Wallis and Student-Newman-Keuls Tests (comparisons). Medians were calculated using mortalities from different concentrations (1-100 ppm) after 24 hours. Different numbers indicate significant $(p<0.05)$ differences in the same column. Different letters indicate significant $(p<0.05)$ differences in the same row. 
Calculated lethal concentrations (LC) varied within the mosquito and anuran species tested. Anopheles darlingi larvae and adults presented the lowest $\mathrm{LC}_{50}(<1 \mathrm{ppm})$ for L. Knudseni; however, Aedes aegypti presented a lower $\mathrm{LC}_{50}$ for $P$. vaillanti skin secretions (Table 1 ).

Despite the lower differences in the mortality of adults and larvae of both mosquito species exposed to P. vaillantii skin secretions, An. darlingi was more susceptible to frog skin secretions tested than Ae. aegypti (Table 2).

Erspamer [13] argues that nearly every species of Leptodactylus is characterized by a particular composition of biogenic amines. In this sense, Roseghini et al. [19], after analyzing different alkylamines from 140 species of American frogs, stated that none of the other species studied can compete with Leptodactylus regarding the variety and richness of aromatic monoamines.

Biogenic amines, e.g. phenylalkylamines such as leptodactyline, have marked neuromuscular-blocking effects on mammals and $\mathrm{LD}_{50}=235 \mathrm{mg} / \mathrm{kg}$ in mice [20].

Phyllomedusa species display a very rich mixture of biologically active peptides, including antimicrobial, central nervous and smooth muscle activity [] and many are known to display biological activity against important tropical diseases such as leishmaniasis and malaria parasites [6,10].

These results agree with those obtained by Weldon et al. [15], which reported that Ae. aegypti had behavioral changes upon landing after contact with toxins, such as pumiliotoxin, from dendrobatid frogs in just a few minutes after the test. Additionally, Williams et al. [16] reported that Lucilia cuprina blowflies died 4-15 minutes after tarsal contact with the skin secretion from the hylid green tree frog, Litoria caerulea (Anura: Hylidae) and ingestion of venom from Litoria caerulea (Anura: Hylidae) in a sucrose solution - $25 \%$ skin secretion (much higher concentration than used in this study) - by the blowfly Calliphora stygia provoked $60 \%$ mortality after 24 hours.

\section{Conclusion}

These experiments indicate that the skin secretions from Leptodactylus knudseni and Phyllomedusa vaillantii contain bioactive molecules with potent insecticide activity. Both species belongs to anuran families that are described as rich sources of biomolecules, several of them without knowledge about their biological activity, such as hyposins from Phyllomedusa skin secretions. The isolation and characterization of the insecticidal molecules present in anuran skin secretions is the objective of further efforts that will be necessary in order to elucidate some aspects of the anurans and mosquito evolution, as well as their potential as source of new molecules for insecticide development.

\section{Ethics committee approval}

The present study was approved by the Brazilian Institute of Environment and Renewable Natural Resources
(IBAMA 17983-1, 27131-2, 27131-3) and Council for the Management of Genetic Resources (CGEN 010627/ 2011-1).

\section{Competing interests}

The authors declare that there are no competing interests.

\section{Authors' contributions}

FTIT and AAS conceived this study, designed the experiments and analyzed data. ÂAS, AAM, TBR, AMS, RGS and LAC contributed to animal material collection and crude venom analysis. All authors contributed equally to the writing and revision of the article. All authors read and approved the final manuscript.

\section{Acknowledgments}

The authors are grateful to Mariluce R. Messias (UNIR - Rondônia, Brazil) and Albertina P. Lima (INPA - Amazonas, Brazil) for providing the animals. Thanks are also due to the Ministry of Science and Technology (MCT), the National Council for Scientific and Technological Development (CNPq), Financier of Studies and Projects (FINEP), State of Acre Technology Foundation (FUNTAC/ FDCT), Coordination for the Improvement of Higher Education Personnel (CAPES) - Project NanoBiotec, Biodiversity and Biotechnology Network of Legal Amazonia (BIONORTE/CNPq/MCT), National Institute for Translational Research on Health and Environment in the Amazon Region (INCT-INPeTAm/ CNPq/MCT), National Institute of Science and Technology on Toxins (INCT-Tox), National Institute for Science, Technology and Innovation for Amazonian Biodiversity (INCT-CENBAM), Program for Biodiversity Research (PPBio), and Secretariat of Development of Rondônia State (SEPLAN/PRONEX/CNPq) for financial support. The authors would also like to thank the Brazilian Institute of Environment and Renewable Natural Resources (IBAMA 17983-1, 27131-2, 27131-3) and Council for the Management of Genetic Resources (CGEN 010627/2011-1) for license expedition.

\section{Author details}

${ }^{1}$ Laboratory of Insect Bioecology, Department of Biology, Federal University of Rondônia (UNIR), Porto Velho, Rondônia State, Brazil. ${ }^{2}$ Oswaldo Cruz Foundation - Rondônia (Fiocruz - Rondônia), Porto Velho, Rondônia State, Brazil. ${ }^{3}$ Center for the Study of Biomolecules Applicable to Health, Oswaldo Cruz Foundation - Rondônia, and Department of Medicine, Federal University of Rondônia (UNIR), Porto Velho, Rondônia State, Brazil.

Received: 6 January 2014 Accepted: 24 June 2014

Published: 2 July 2014

References

1. Forattini OP: Culicidologia médica: Identificação, Biologia, Epidemiologia, Volume II. São Paulo: EdUSP; 1996.

2. World Health Organization: Resources for prevention, control and outbreak response Dengue, Dengue Haemorrhagic fever. Geneva: World Health Organization; 2011.

3. Secretaria de Vigilância em Saúde: Sistema de Informação de Vigilância Epidemiológica - Malária (Sivep-Malária). Brasília: Ministério da Saúde; 2014. http://www.who.int/malaria/publications/world_malaria_report_2013/en/.

4. Gil LHS, Tada MS, Katsuaragowa TH: Urban and suburban malaria in Rondônia (Brazilian western Amazon) II: perennial transmission whit high anopheline densities are associated with human environmental changes. Mem Inst Oswaldo Cruz 2007, 102:271-276.

5. Organização Pan-Americana da Saúde, Organização Mudial da Saúde: Dados da dengue no Brasil, 2013. Brasília: Ministério da Saúde; 2013. http://www.paho.org/ bra/index.php?option=com_content\&view=article\&id=3159\&ltemid=1.

6. Calderon LA, Silva-Jardim I, Zuliani JP, Silva Ade A, Ciancaglini P, Silva LHP, Stábeli RG: Amazonian biodiversity: a view of drug development for Leishmaniasis and malaria. J Braz Chem Soc 2009, 20(6):1011-1023.

7. Calderon LA, Soares AM, Stábeli RG: Anuran Antimicrobial Peptides: an alternative for the development of nanotechnological based therapies for multi-drug-resistant infections. Signpost Open J Biochem Biotech 2012, 1:1-11.

8. Azevedo-Ramos C, Reynolds R, La Marca E, Coloma LA, Ron S: Phyllomedusa vaillantii, 2010. In IUCN 2012. IUCN red list of threatened species. 2012. http://www.iucnredlist.org/details/55868/0. 
9. Calderon LA, Silva Ade A, Ciancaglini P, Stábeli RG: Antimicrobial peptides from Phyllomedusa frogs: from biomolecular diversity to potential nanotechnologic medical applications. Amino Acids 2010, 40(1):29-49.

10. Calderon LA, Stábeli RG: Anuran amphibians: a huge and threatened factory of a variety of active peptides with potential nanobiotechnological applications in the face of amphibian decline. In Changing Diversity in Changing Environment. Edited by Grillo O, Venora G. Rijeka: InTech - Open Access Publisher; 2011:211-242.

11. Heyer R, Coloma LA, Ron S, Azevedo-Ramos C, La Marca E, Hardy J: Leptodactylus knudseni. In IUCN 2012. IUCN red list of threatened species. 2012.

http://www.iucnredlist.org/details/57135/0.

12. Erspamer V: Biogenic amines and active polypeptides 6516 of the amphibian skin. Annu Rev Pharmacol 1971, 11:327-350.

13. Erspamer V, Roseghini M, Cei JM: Indole-, imidazole-, and phenylalkylamines in the skin of thirteen Leptodactylus species. Biochem Pharmacol 1964, 13:1083-1093.

14. Toledo RC, Jared C: Cutaneous granular glands and amphibian venoms. Comp Biochem Phys A 1995, 111(1):I-29.

15. Weldon PJ, Kramer M, Gordon S, Spande TF, Daly JW: A common pumiliotoxin from poison frogs exhibits enantioselective toxicity against mosquitoes. Proc Natl Acad Sci U S A 2006, 103(47):17818-17821.

16. Williams CR, Wallman JF, Tyler MJ: Toxicity of green tree frog (Litoria caerulea) skin secretion to the blowflies Calliphora stygia (Fabricius) and Lucilia cuprina (Wiedemann) (Diptera: Calliphoridae). Aust J Entomol 1998, 37(1):85-89.

17. Williams CR, Smith BPC, Best SM, Tyler MJ: Mosquito repellents in frog skin. Biol Lett 2006, 2(2):242-245.

18. World Health Organization: Guidelines for laboratory and field-testing of mosquito larvicides. Geneva: World Health Organization; 2005.

19. Roseghini M, Erspamer V, Erspamer GF, Cei JM: Indole-, imidazole- and phenyl-alkylamines in the skin of one hundred and forty American amphibian species other than bufonids. Comp Biochem Physiol C 1986, 85(1):139-147.

20. Erspamer V, Glasser A: The pharmacological actions of ( $m$-hydroxyphenethyl)trimethylammonium (leptodactyline). Br J Pharmacol Chemother 1960 15(1):14-22.

doi:10.1186/1678-9199-20-28

Cite this article as: Trindade et al:: Insecticidal activity of Leptodactylus knudseni and Phyllomedusa vaillantii crude skin secretions against the mosquitoes Anopheles darlingi and Aedes aegypti. Journal of Venomous Animals and Toxins including Tropical Diseases 2014 20:28.

\section{Submit your next manuscript to BioMed Central and take full advantage of:}

- Convenient online submission

- Thorough peer review

- No space constraints or color figure charges

- Immediate publication on acceptance

- Inclusion in PubMed, CAS, Scopus and Google Scholar

- Research which is freely available for redistribution 